\title{
A Proposed Model for Establishing An Information System for the Blood Bank (To be Applied in the Misr University)
}

by

\section{Ahmed Mohammed Abd EI Raheem MSc. Candidate \\ Sadat Academy for Management Sciences}

\author{
Prof dr. Farahat Farag Farahat \\ Dept. of Computer and Information Systems \\ Sadat Academy for Management Sciences
}

\begin{abstract}
This work presents designing an information system that can facilitate reaching to the blood groups and derivatives through data base including information about the numbers and types of blood groups and derivatives as well as information about the donors. The present study aims at the hospitals and the Ministry of health, where there is no system that facilitates calculating the numbers and types of blood and indicating its availability. Therefore, the study is geared to developing an online blood banking website that is expected to help blood banking, and develop an online Blood Donation Information.
\end{abstract}

Keywords: OBB,BB,BBS,MS,IS,MUST,BMIS,OBBS,IT,MIS

\section{Introduction}

The entire information system project development has to keep in mind the distributed client server computing technology. The Blood Donation Agent is to create an eInformation about the donor and organization that are related to donating the blood. The Information System has been designed to perform around the Storage or number of stored units, showing all its movements in real time. A storage of blood components can have different input resources and output such as issue for other branches or for transfusion and withdrawal blood that is not in good condition. Modern medical care, including surgery and medical treatment for many diseases, is not possible without the use of blood products. A shortage of blood products means that someone may not get prompt. Adequate care for those undergoing major surgery, and for others suffering from blood loss are to be considered carefully. Blood transfusions are also used to treat severe anemia resulting from other causes such need calls for introduction of a blood reservation concept called blood banks where the collected bloods are stored until needed. Therefore, this study tries to develop online blood banking (OBB) which will link all private banks of hospitals within one city with clear access to blood samples in real time and the right place, and consequently solve non-availability of blood resulting from lack of information. The benefit of developing the (OBB) is to link all blood banks within a wide geographical location to enable the user to share information in a more effective manner. The information system will automatically update the information related to the stored blood. This research serves humanity by preventing many disasters associated with non-availability of blood when needed.

\section{Proposed System}

The online blood bank keeps the name of the donor who is donating blood as a unique id.

The system provides statistics on blood availability within blood banks, registered donors for specific area from the hospitals and blood banks.

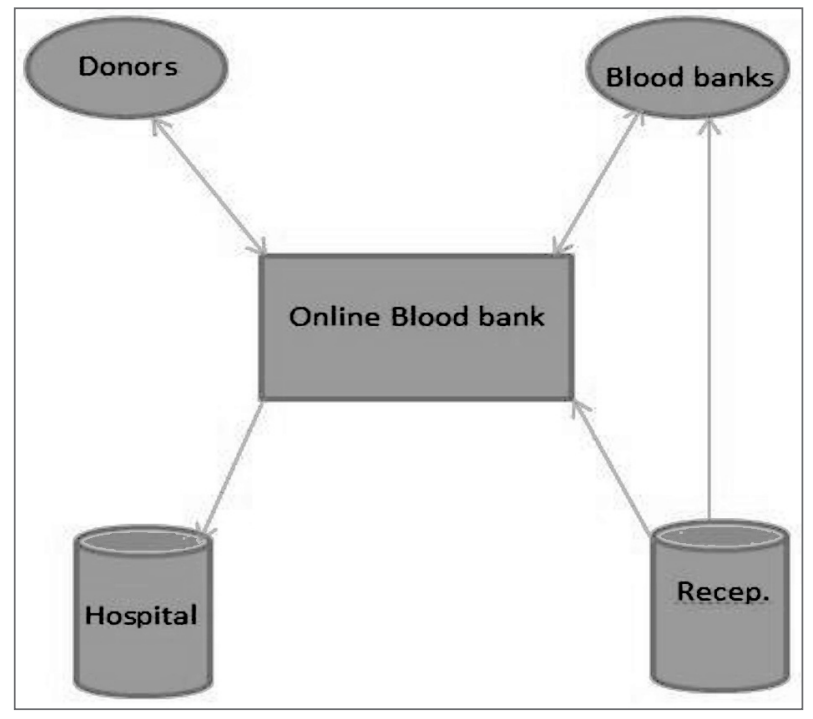

Fig. (1)

System Architecture 


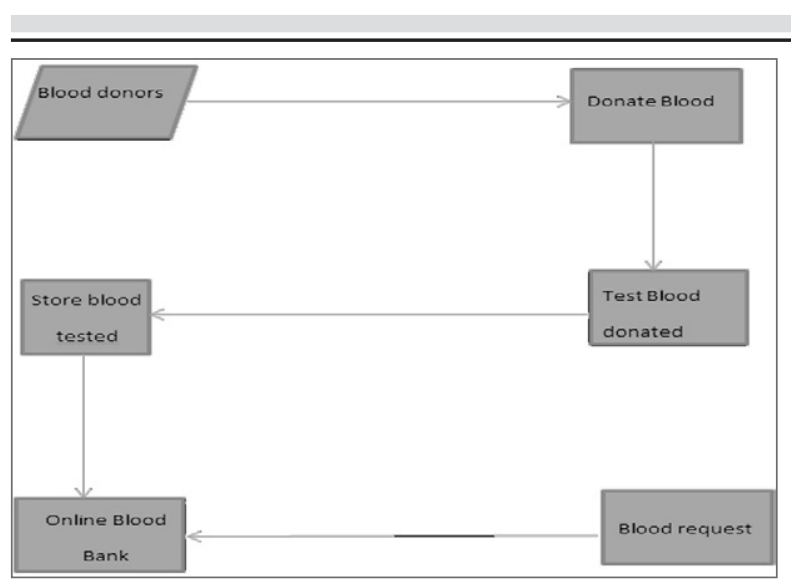

Fig. (2)

Model of the Online Blood Bank

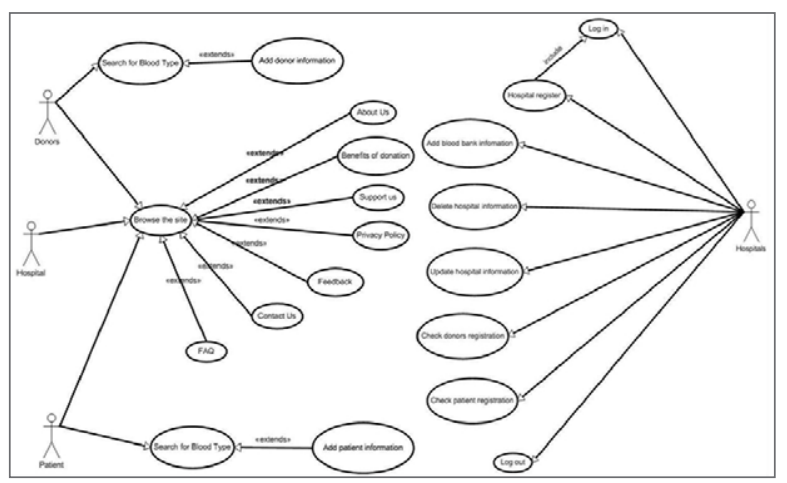

Fig. (3)

Case Diagram

\section{Research Questions}

The questions are as follows:

- How can the inventory management in BB be guaranteed?

- How can we develop a BBS?

- How can the information technology contribute to following up the different types and derivatives of blood groups through an information system that can ensure saving the lives of patients?

- In what ways can overall inventory management in BB be guaranteed?

- How can we develop an OBB system capable of handling excessive blood collection and inventory management?

- What is the usability of the developed prototype?

\section{Research Objective}

The objectives of the study are to:-

$\checkmark$ Identify the reality of management systems, blood bank, and the need for an information system for management, and access to a range of administrative and technical models that can be relied upon in the management of information systems in blood banks.

$\checkmark$ Reach a set of principles and requirements that can be relied upon when building an information system to manage the branches of the blood banks.

Among these principles and requirements to achieve answering these two main questions are:

- Having easy and rapid access to blood groups and their derivatives of the branches of circulating blood banks in the country.

- Ensuring abundance of blood bags and derivatives of various factions in all branches of the blood bank with adequate quantities.

- Maintaining the validity of blood bags by selecting the appropriate amounts for each branch of the blood banks.

\section{Objectives of the study}

1. To identify ways by which excess collection of blood can be controlled and overall inventory management can be guaranteed.

2. To develop an online internet blood banking capable of handling inventory management.

3. To determine the usability of the developed prototype.

The main objective of the study is to create an electronic blood donor management

information system in order to assist in the management of blood donor records, planning

and sharing information in a more confidential, convenient and secure way using modern

technology.

Therefore, this research aims to:

- Identify the reality of MS, BB, and the need for an information system for management, and access to a range of administrative and technical models that can be relied upon in the management of information systems, in blood banks.

- To reach a set of principles and requirements that can be relied upon when building an information system to manage the branches of the blood banks.

- One of these principles and requirements is the easy and rapid access to Blood

groups and their derivatives of the branches of circulating $B B$ in the country.

-The abundance of blood bags and derivatives of various factions in all branches of 
the blood bank with adequate quantities.

-To maintain the validity of blood bags by selecting the appropriate counts for each branch of branches of the blood banks.

\section{Importance of the study}

The design of such a model will help patients who suffer from particular problems with

blood, as well as in cases of major accidents and critical cases where the time factor is of

great importance through the organization and automatic control of IS in BB.

This study is important to blood donors because it aims at addressing problems of security,

secrecy and confidentiality of blood donor records.

It also attempts to monitor delays, errors, inconsistencies in medical records and timely

access to historical records, all of which have a farfetched impact on planning and decision-

making.

The study is expected that will result in the following benefits:

1- It will ease the control and distribution of blood in various parts of the country based on hospitals demands.

2- Automated data acquisition and quick access to medical records by the legal users of the system will be assured.

3- It will continue to improve on the planning and decision-making process by providing to management timely, secure and confidential medical reports related to blood donation.

4- It will improve medical service delivery due to timely and easy generation of management exports by the relevant entities.

5- The study will benefit MUST management, which will find it easy to strategically plan, coordinate and take decisions concerning BDR activities.

6- MUST counselors will be able to keep confidentiality of the donor's results and disseminate blood results to donors with ease.

7- The automation of the data collection process will simplify the work of the data clerks.

7. Results of the Study:

The most significant results of this study are:

1- Managing the records of donors, BB centers, and re- cipients.

2- Reducing human error when employees keep the records.

3- Each hospital or BB center can register on the website and make its own account that contains information about the hospital: the blood types needed and the blood types available.

4- Encouraging voluntary blood donations.

5- Making it easier for donors to find the appropriate recipients for whom to donate blood by searching in the website by blood type; a list of BBS that need that blood type will appear.

6- Making it easier for recipients to find the appropriate donors by searching in the website by his blood type.

7- Developing a BMIS to manage the records of blood donors.

8- Educating the community on the benefits of blood donation.

9- Collecting donor's information easily and efficiently.

10- Increasing the number of donors by increasing the facilities provided to them.

11- Providing fast and easy accessible system for patients and donors.

12- The system is able to handle emergency situations and the BB centers will have enough blood for all patients by receiving the required blood.

\section{Conclusions}

This research aimed to develop an OBBS to be made use of to overcome the problem of shortage in the amounts of blood in the BB, and by connecting the branches of the bank through the internet to make it easier for them to share the available amounts of blood. This service is considered a humanitarian one. In the world of IT where the entire world is becoming a global village, where end user can get the information while sitting at home by only one click. In fact the government has taken a step in order to transform the system. MIS helps to make the system paper less. All the money transaction is made possible because of the MIS. The researcher believes that developing the management information system for the blood bank brings revolutionary changes in the system. It is a small contribution of the researcher in order to serve mankind. It can save lives by educating the public about the benefits of blood donation, encourage them to donate, and manage the records 
of donors and people who need blood, to help the people who need blood to find the appropriate donors as soon as possible in quick, perfect, and a safe way with less effort. Therefore, the results from this study can be used as a basis, a stepping stone, a roadmap or a starting point for future research and studies related to this topic.

\begin{tabular}{|c|c|}
\hline ABB & Description \\
\hline OBB & Online Blood Bank \\
\hline BB & Blood Bank \\
\hline BBS & Blood Bank System \\
\hline MS & Management System \\
\hline Is & Information System \\
\hline MUST & Misr University For Science \& Technology \\
\hline BMIS & Blood Management Information System \\
\hline OBBS & Online Blood Bank System \\
\hline IT & Information Technology \\
\hline MIS & Management Information System \\
\hline
\end{tabular}

\section{REFERENCES}

1. Armstrong, E., Ball, J., Bodoff, S., Carson, D. B., Evans, I.,Green,D.,et al. (2004). The J2EETrademarked 1.4 Tutorial Sun Microsystems, 4150.

2. Best, J. W., \& Kahn, J. V. (2003). Research in education (9th ed.). Boston: Allyn\& Bacon.

3. Dobing, B., \& Parsons, J. (2006). How UML is Used. Communications of the ACM, 49(5), 109-113.

4. Disaster Operations Handbook (2003). Coordinating the Nation's Blood Supply during Disasters Biological Events, American Association of Blood Banks (AABB).

5. Gellersen\&Gaedke, M. (1999). Object-Oriented Web Application Development. IEEE Internet Computing, 3(1), 6068.

6. George, J. F., Batra, D., Valacich, J. S., \& Hoffer, J. A. (2004). Object-Oriented Systems Analysis and Design. Upper Saddle River, NJ: Prentice Hall.

7. Guangpeng, L., Zhongwen, G., Song, X. \&Wenh, P. (2009). 8. Glinz M. (2007). On Non-Functional Requirements. 15th IEEE International Requirements Engineering Conference (RE'07), Delhi, India.

9. Kamran S, Mohammad. Y\& Douglas. D. (2007). MinedKnowledge and Decision Support Services in Electronic Health. IEEE Computer Society.

10. Khan, A. R. \&Qureshi, M. S. (2009). Web-Based Information System for Blood Donation, International Journal of Digital Content Technology and its Applications, 3, (2), $137-142$.

11. Kim, D. U (2002). The Quest for Quality Blood Banking Program in the New Millennium the America way, Interna- tional Journal of Hematology, or Supplement II, 258 - 262. 12. Kim, D., Yoo, S. K., Kim, H., Chang, B., Bae, H. \& Kim, S. (2007). Location Based Blood Bag Management using active RFID and Ubiquitous sensor network. 6th International Special Topic Conference on ITAB, Tokyo, IEEE Xplore, $p$ $320-322$.

13. Kothari, C. R. (1985), Research Methodology Methods and Techniques, Delhi: Wiley Eastern Limited.

14. Kruchten, P. (2000). The Rational Unified Process An Introduction (Second ed.). Canada: Addison Wesley.

15. Laudon, K. C., \&Laudon, J. P.(2000). Management information Systems: Prentice Hall PTR Upper Saddle River, NJ, USA.

16. Li, B. N. \& Dong, M. C. (2006). Banking on blood. JET Computing and Control Engineering, p22 - 25.

17. Li, B. N.. Dong, M. C. \& Chao, S. (2008). On decision making support in blood bank information systems, Expert Systems with Applications, 34, (2008), 1522 - 1532.

18. Li, B., Dong, M. \&Mang, V. (2005). From Codabar to ISBT 128: Implementing Barcode Technology in Blood Bank Automation System. IEEE Xplore.

19. Lewis, J. R. (1995) IBM Computer Usability Satisfaction International Journal of Human-Computer Interaction, 7:1, 57-78.

20. Lipscomb J and L Rosenstock. 1997. Health care workers: Protecting those who protect our health.

21. Nielson,J. (1993). Usability Engineering. San Diego, CA: Morgan Kaufmann

22. Nwaiwu, C. I. (2005). A Web-based System for Student Evaluation of Teaching Quality. The University Of Sheffield. 23. Oba, Y., Otani, S., Yasuda, N. \& Terada, K. (2001) Management of blood donor examination by computers .RinshoByori. v19iSuppl. 422.

24. Oliveri, J. (2008). Blood is the Lifeline, The Beginning Blood Line, 1, (1), 1

25. Rational Software White paper (1998). Rational Unified Process: Best Practices for software Development teams. Rational, the software development company.

26. Sun, (2010). j2ee. Retrieved March 15, 2010, fromwww java .sun.com/j2ee/overview

.html.

27. Spool, J., \& Schroeder, W. (2001). Testing web sites: Five users is nowhere near enough. In CHI 2001 Extended Abstracts (pp. 285-286). New York: ACM Press.

28. Virzi, R. A. (1992). Refining the test phase of usability evaluation: How many subjects is enough? Human Factors, 34, 457-468.

29. The American Heritage Medical Dictionary, 2007, 2004 
by Houghton Mifflin Company.

30. Encyclopedia of Medicine, 2008, The Gale Group.

31. Mosby's Medical Dictionary, 2009, Elsevier

32. Goodnough LT. Transfusion medicine. In: Goldman L, Ausiello D, eds.Cecil Medicine., Pa: Saunders Elsevier; 2007:chap 183

33. Hannu Jaakkola and Bernhard Thalheim . (2011) "Architecture-driven Modeling methodologies."In: Proceedings of the 2011 conference on Information Modelling and Knowledge Bases XXII. AnneliHeimbürgeret al. (eds). IOS Press. p. 98

34. Paul C. Clements (1996) "A survey of architecture description languages." Proceedings of the 8th international workshop on software specification and design.IEEE Computer Society, 1996.

35. Nenad Medvidovic and Richard N. Taylor (2000). "A classification and comparison framework for software architecture description languages." Software Engineering, IEEE Transactions on 26.1 (2000): 70-93.

36. A Web-based blood donor management information system for the Red Cross Society,

Uganda .Kanobe Fredrick

37. HTML, Steven Holzner (Black Book)

38. ACTIVE SERVER PAGE, John Kauffman, Stephen Walther.

39. Nielson, J. (1993). Usability Engineering. San Diego,

CA: Morgan Kaufmann

40. Nielsen, J. (2000, March). Why you only need to test with 5 users: Alertbox.

\section{Web Sites References}

41. American Blood Centers (2008).ABC Unveils Robust

Blood Inventory

Management IT System, ABC News letter. Retrieved March 14, 2010, from,

www.americasblood.org

42. Bank, S. D. B. (2002). Blood Donation. Retrieved on

March14,2010, from:

www.sandiegobloodban.k.org

43. Boujtita, N (2008). Improving Blood Banking protocols using the Thermo Scientific

RсзBP Plus TM. Thermo Fisher Scientific Inc. Retrieved

17January 2010, from

www.thermo.com.

44. Dougherty, D. (2001). LAMP: The Open Source Web Platform. Retrieved

March2010 from: www.onlamp.com/pub/a/onlamp/2001/01/25/lamp.html.
45. Farlex. (2010). Blood Donation and Registry. The Free Dictionary Retrieved on

17January 2010 from: http://medical-dictionary .thefreedictionary.com/Blood

+Donation+ and+ Registry.

46. Johan, 2004 Information System Analysis And Design, Retrieved on 15 March

2010, from: http://Www.Cs.Toronto.EduP1m/3405/Slides2/ SequenceD.Pdf

47. Nielsen, J. (2000, March). Why you only need to test with 5 users: Alertbox.

Retrieved on March on 15, 2010 from: http://www.useit. com/alertbox/20000319.html.

48. The free library. (2005). MySQL--DBMS. Retrieved on March 15, 2010, from:

http://www.thefreelibrary.com/MySQL--DBMS.-

a0163332714.

49. Vaishnavi, V. \&Kuechler, W. (2004). Design Research in Information Systems.

Retrieved on 17 January 2010 from:

http://www.isworld .org/Research design/drisISworld.htm.

50. WebService20. (2004). Apache. Retrieved on 15 March 2010, from:

http://webservice20.com/glossary-articles/apache.html 51. http://www.pbs.org/wnet/redgold

52.http://learn.genetics.utah.edu/content/begin/traits/ blood/types.html

53. http://anthro.palomar.edu/blood/ABO_system.htm 54.http://www.wisegeek.net/what-is-a-blood-bank-system.htm\#slideshow

55. http://www.projectconnections.com/templates/detail/ use-case-

specification.html 61.

56. http://www.luminantdesign.com/definitions/userinterfacedesign.html

57. http://searchsoftwarequality.techtarget.com/definition/ waterfall-model.html

58. The free library. (2005). MySQL--DBMS. Retrieved on March 15, 2010, from:

http://www.thefreelibrary.com/MySQL--DBMS.-

a0163332714.

59. What are Php and Mysql .(2013)-Bradley. Retrieved on March 15,2014, from:

http://Php.About.com/od/phpbasics/ss/php_Mysql_2.html 60.Quinstreet Inc. Javascript.(2013). Retrieved March 13, 2014, from

http://www.webopedia.com/Term/J/Javascript.html 